\title{
Obesity and Gastroesophageal Reflux: Quantifying the Association Between Body Mass Index, Esophageal Acid Exposure, and Lower Esophageal Sphincter Status in a Large Series of Patients with Reflux Symptoms
}

\author{
Shahin Ayazi • Jeffrey A. Hagen • Linda S. Chan • Steven R. DeMeester • \\ Molly W. Lin • Ali Ayazi • Jessica M. Leers • Arzu Oezcelik • Farzaneh Banki • \\ John C. Lipham • Tom R. DeMeester • Peter F. Crookes
}

Received: 15 April 2009 /Accepted: 11 May 2009/Published online: 28 May 2009

(C) The Author(s) 2009. This article is published with open access at Springerlink.com

\begin{abstract}
Introduction Obesity and gastroesophageal reflux disease (GERD) are increasingly important health problems. Previous studies of the relationship between obesity and GERD focus on indirect manifestations of GERD. Little is known about the association between obesity and objectively measured esophageal acid exposure. The aim of this study is to quantify the relationship between body mass index (BMI) and 24-h esophageal $\mathrm{pH}$ measurements and the status of the lower esophageal sphincter (LES) in patients with reflux symptoms.

Methods Data of 1,659 patients (50\% male, mean age 51 14 ) referred for assessment of GERD symptoms between 1998 and 2008 were analyzed. These subjects underwent 24-h pH monitoring off medication and esophageal manometry. The relationship of BMI to 24-h esophageal $\mathrm{pH}$ measurements and LES status was studied using linear regression and multiple regression analysis. The difference of each acid exposure component was also assessed among four BMI subgroups (underweight, normal weight, overweight, and obese) using analysis of variance and covariance.

Results Increasing BMI was positively correlated with increasing esophageal acid exposure (adjusted $R^{2}=0.13$ for the composite $\mathrm{pH}$ score). The prevalence of a defective LES was higher in patients with higher BMI $(p<0.0001)$. Compared to patients with normal weight, obese patients are more than twice as likely to have a mechanically defective LES [OR=2.12 $(1.63-2.75)]$.

Conclusion An increase in body mass index is associated with an increase in esophageal acid exposure, whether BMI was examined as a continuous or as a categorical variable; $13 \%$ of the variation in esophageal acid exposure may be attributable to variation in BMI.
\end{abstract}

Keywords Obesity · Gastroesophageal reflux disease (GERD) · BMI · Comorbidity · Ambulatory pH monitoring · Lower esophageal sphincter (LES)

S. Ayazi $\cdot$ J. A. Hagen $\cdot$ L. S. Chan $\cdot$ S. R. DeMeester $\cdot$

M. W. Lin J. M. Leers $\cdot$ A. Oezcelik $\cdot$ F. Banki J. C. Lipham •

T. R. DeMeester $\cdot$ P. F. Crookes $(\bowtie)$

Department of Surgery, Keck School of Medicine,

University of Southern California,

1510 San Pablo St, Ste 514,

Los Angeles, CA 90033, USA

e-mail: crookes@surgery.usc.edu

A. Ayazi

Department of Electrical Engineering, University of California,

Los Angeles, CA, USA

\section{Introduction}

Gastroesophageal reflux disease (GERD) is a major health problem. Epidemiologic studies have shown that the prevalence of GERD in Western countries is approaching $20 \%{ }^{1}$ This increased prevalence appears to be accelerating. A meta-analysis conducted in 2007 of reports published over the past 20 years suggested that the prevalence has increased by $4 \%$ year in the Western world. ${ }^{2}$ In North America, the incidence increased 5\% annually between 1992 and 2005 . $^{2}$

Obesity has also increased in prevalence during the same period of time. ${ }^{3}$ In 1980 , the National Health and Nutrition Examination Survey II (NHANES II) reported that the 
prevalence of obesity among US adults between the ages of 20 and 75 was $15 \%$. By 2003-2004, the NHANES III study reported that the prevalence of obesity had more than doubled in the 25 years between the studies. ${ }^{4}$ It is predicted that by the year $2020,77.6 \%$ of men will be overweight and $40.2 \%$ obese; the corresponding predictions for women are $71.1 \%$ overweight and $43.3 \%$ obese. $^{5}$

The parallel rise in GERD and obesity suggests a link between the two. A recent meta-analysis of 20 studies reported a positive association between increasing body mass index (BMI) and the presence of GERD within the USA. ${ }^{6}$ Further, in many chronic diseases such as cardiovascular diseases, cancer, arthritis, and diabetes, obesity appears to be a substantial etiologic factor. Therefore, it is reasonable to enquire if obesity may contribute to the increased prevalence of GERD. However, the literature on this subject is conflicting. ${ }^{7-11}$ This conflict may be due to differences in the definition of GERD: surveys that define GERD based on symptom questionnaires may be overinclusive, ${ }^{8,10}$ whereas those based on complications of GERD such as esophagitis, Barrett's esophagus, or esophageal adenocarcinoma are too restrictive. ${ }^{12-15}$

To establish a more convincing relationship between obesity and GERD, the diagnosis of GERD must be made with greater precision. The most objective method of defining GERD is $24-\mathrm{h}$ esophageal $\mathrm{pH}$ monitoring. Additional insight into the physiological mechanism underlying the relationship between obesity and GERD requires studies such as esophageal manometry. The invasive nature of these tests precludes their application to large populations of patients. For this reason, there is no large study that has correlated BMI with esophageal acid exposure and lower esophageal sphincter (LES) function. The aim of this study is to quantify the relationship between BMI and esophageal acid exposure and LES status in a large number of symptomatic patients.

\section{Methods}

Data were collected on 2,723 subjects with foregut symptoms referred to the Esophageal Diagnostic Laboratory at USC University Hospital between October 1998 and August 2008 who underwent esophageal pH monitoring. The subjects were weighed by laboratory personnel on arrival at the esophageal laboratory. In most cases, height was also measured, but in a small minority of patients, selfreported height was used. BMI was calculated as weight in $\mathrm{kg} /$ (height in $\mathrm{m})^{2}$. The World Health Organization categories of BMI were used to group the patients into four standard categories: underweight $<18.5$, normal weight $18.5-24.9$, overweight $25-29.9$, and obese $\geq 30$. All subjects had esophageal manometry of the LES and esophageal body and 24-h esophageal $\mathrm{pH}$ monitoring. Subjects were excluded if there was a technical problem with the test, if the studies were conducted while on acid suppression medication, or if they had a history of previous foregut surgery. Subjects found to have a named motility disorder of the esophageal body (achalasia, diffuse esophageal spasm, and nutcracker esophagus) were also excluded. As a result, 638 subjects were excluded. Of the remaining 2,085 subjects, 1,659 underwent a detailed assessment of the LES using slow motorized pull-through manometry. These 1,659 subjects constituted the study population of this investigation.

\section{Esophageal Manometry}

All drugs interfering with foregut function were discontinued for at least $48 \mathrm{~h}$ before the study. After an overnight fast, a 12 French 8-channel water-perfused motility catheter (Arndorfer Medical Specialties, Greendale, WI, USA) was passed through the anesthetized nostril into the esophagus and into the stomach. The manometry study was conducted and analyzed as previously described. ${ }^{16}$

Detailed assessment of the LES was performed using slow motorized pull-through manometry. The conduct and analysis of this method has been reported by us previously. ${ }^{17}$ This technique has been shown to have superior accuracy and reproducibility compared to the standard manometry. ${ }^{17}$ Three characteristics of the LES were assessed: pressure, total length, and abdominal length. When all three components of the LES were normal, the LES was considered mechanically normal and when one or more components were abnormal, the LES was considered mechanically defective.

For the purpose of graphical representation, the LES was stratified on an ordinal scale of $0-3$, according to the number of LES components (resting pressure and total and abdominal length) within the normal range: 0 , all components defective; 1 , only one component normal; 2, two components normal; 3 , all three components normal.

\section{Detection of Hiatal Herniation}

The presence of hiatal hernia was defined manometrically by the presence of a double hump pattern. This pattern is created by separation of the manometrically observed highpressure zone in the distal esophagus into two distinct locations with a near-baseline pressure between. ${ }^{18}$

\section{Ambulatory 24-h Esophageal pH Monitoring}

Acid-suppression medications were discontinued 3 days ( $\mathrm{H}_{2}$-blocking agents) or 14 days (proton pump inhibitors) before the study. The $\mathrm{pH}$ catheter with an antimony sensor 
was calibrated in a standard buffer solution at $\mathrm{pH} 1$ and 7 before and after monitoring. The catheter was passed transnasally in order to position the $\mathrm{pH}$ sensor $5 \mathrm{~cm}$ above the manometrically determined upper border of the LES. Subjects were given dietary instruction to be followed throughout the 24-h monitoring period. They were also asked not to eat or drink between meals; to avoid carbonated beverages, alcohol, or fruit juices; to remain upright (sitting, standing, or walking) throughout the day; and to lie flat at night for sleep. They were instructed to keep a diary for the 24-h period indicating the time of meals, when they went to bed, when they got up, and when symptoms occurred. Esophageal acid exposure was expressed by the standard parameters, namely, the percent time $\mathrm{pH}$ was $<4$ for the total monitored period, and the time spent in the upright and supine positions, the number of reflux episodes, the number of reflux episodes longer than $5 \mathrm{~min}$, and the duration of the longest reflux episode. From these six values, a composite $\mathrm{pH}$ score (DeMeester score) was calculated using a commercial software program (PolyGram ${ }^{\circledR}$ ). The software also measured the percent time $\mathrm{pH}$ was $<4$ during the $2 \mathrm{~h}$ immediately following a meal (post prandial period).

The study was approved by the Institutional Review Board (Reference number, HS-07-00573).

\section{Statistical Analysis}

The esophageal 24-h $\mathrm{pH}$ components and the composite $\mathrm{pH}$ score were compared across BMI groups using analysis of variance (ANOVA) to detect an overall difference. The Bonferroni post hoc test was used to detect differences between pairs of groups. The relationship of each 24-h esophageal $\mathrm{pH}$ component with BMI was studied using linear regression and multiple regression analysis to derive the unadjusted and adjusted slope and the 95\% confidence intervals. Age, sex, hiatal hernia, and LES status that were identified as significant risk factors in the univariate analysis were used as regressors in all models. The difference of each acid exposure parameter was also assessed among four BMI groups using analysis of variance and covariance.

We further assessed the significance of the difference of the adjusted slope between men and women using the multiple regression model.

In order to explore whether there is a threshold in BMI above or below which there is no relationship between $\mathrm{pH}$ and BMI, we repeated the analysis of covariance for each cut point of BMI from 25 through 35 and derived the difference of the adjusted means, the $95 \%$ confidence interval (CI), and $R^{2}$.

To assess the relationship between BMI and LES status, we examined the risk of a mechanically defective LES in the four BMI groups adjusting for age, sex, and hiatal hernia using the logistic regression model from which we derived the adjusted odds ratios and the 95\% CI.

We used the SAS statistical analysis system (The SAS System Release 8.02, SAS Institute, Cary, NC, USA) for all analyses. The MATLAB program (MATLAB, The MathWorks; Natick, MA, USA) was used to create a threedimensional model showing interaction between BMI, LES status, and esophageal acid exposure. This was performed by plotting an "empiric spline" surface. A modified ridge estimator was used to generate this surface on a twodimensional grid.

\section{Results}

Of the 1,659 subjects, 835 were women (50\%) and 824 men $(50 \%)$. The mean \pm SD for BMI was $27.7 \pm 5.4$, and the mean age was $51.4 \pm 14.2$. The demographic and physiologic characteristics of the study population including the distribution by BMI categories are shown in Table 1. The

Table 1 Demographic and Physiologic Characteristics of the Study Population $(n=1659)$

\begin{tabular}{lc}
\hline Mean age (SD) & $51.4(14.2)$ \\
Mean BMI (SD) & $27.7(5.4)$ \\
Sex & \\
Male & $824(50.3 \%)$ \\
Female & $835(49.7 \%)$ \\
BMI categories & \\
Underweight (\%) & $16(1.0 \%)$ \\
Normal (\%) & $530(32.0 \%)$ \\
Overweight (\%) & $640(38.6 \%)$ \\
Obese (\%) & $473(28.5 \%)$ \\
LES status & \\
Defective (\%) & $776(46.8 \%)$ \\
Normal (\%) & $883(53.2 \%)$ \\
Hiatal hernia & \\
Present & $715(43.1 \%)$ \\
Absent & $944(56.9 \%)$ \\
Esophageal pH monitoring components & \\
\% Total time & \\
\% Upright time & $8.1(13.0)$ \\
\% Supine time & $9.4(28.9)$ \\
Number of episodes & $6.7(14.1)$ \\
Number of episodes $>5$ & $99(116)$ \\
Longest episode (min) & $3.8(5.6)$ \\
Compost prandial time & $17.1(25.9)$ \\
\hline & $11.7(14.9)$ \\
Com score & $30.4(39.1)$ \\
\hline
\end{tabular}

${ }^{\mathrm{a}}$ Mean (SD) 
Table 2 Esophageal 24-h pH Components and Composite pH Score Compared Across BMI Groups

\begin{tabular}{|c|c|c|c|c|c|}
\hline & Underweight $(n=16)$ & Normal $(n=530)$ & Overweight $(n=640)$ & Obese $(n=473)$ & $p$ value $^{\mathrm{a}}$ \\
\hline$\%$ Total time & $1.28 \pm 1.73$ & $4.76 \pm 8.95$ & $9.16 \pm 15.06$ & $10.81 \pm 13.09$ & $<0.0001$ \\
\hline$\%$ Upright time & $1.77 \pm 2.45$ & $5.10 \pm 7.50$ & $11.59 \pm 44.37$ & $11.51 \pm 13.31$ & $<0.0001$ \\
\hline$\%$ Supine time & $0.21 \pm 0.44$ & $3.39 \pm 7.90$ & $7.36 \pm 15.05$ & $9.55 \pm 17.33$ & $<0.0001$ \\
\hline Number of episodes & $28.6 \pm 29.0$ & $60.0 \pm 72.4$ & $108.8 \pm 122.1$ & $131.8 \pm 134.2$ & $<0.0001$ \\
\hline Number of episodes $>5 \mathrm{~min}$ & $0.44 \pm 1.26$ & $2.21 \pm 3.39$ & $4.12 \pm 5.96$ & $5.09 \pm 6.61$ & $<0.0001$ \\
\hline Longest episode & $3.81 \pm 5.31$ & $11.58 \pm 15.60$ & $19.00 \pm 26.59$ & $21.30 \pm 32.49$ & $<0.0001$ \\
\hline$\%$ Post prandial time & $2.73 \pm 4.24$ & $7.45 \pm 10.62$ & $12.63 \pm 15.78$ & $15.41 \pm 16.70$ & $<0.0001$ \\
\hline Composite $\mathrm{pH}$ score & $5.57 \pm 6.25$ & $17.73 \pm 23.18$ & $33.44 \pm 40.60$ & $41.42 \pm 46.92$ & $<0.0001$ \\
\hline
\end{tabular}

Underweight $<18.5$, Normal 18.5-24.9, Overweight 25-29.9, Obese $\geq 30$

${ }^{a}$ One-way analysis of variance

mean \pm SD for the components of the $\mathrm{pH}$ record by BMI groups are shown in Table 2. A significant stepwise increase in all parameters of esophageal acid exposure was observed with increasing BMI category. The differences between individual BMI groups using a global measure of esophageal acid exposure (composite $\mathrm{pH}$ score) is shown graphically in Fig. 1.

\section{Other Factors}

In addition to BMI, we investigated the role of age, sex, hiatal herniation, and presence of a defective LES on esophageal acid exposure. Table 3 provides a comparison of the mean composite $\mathrm{pH}$ score between subgroups of these factors. Older age, male sex, hiatal herniation, and presence of a mechanically defective LES are all significant contributing factors for higher composite $\mathrm{pH}$ score. The above factors were then included as regressors in the multiple regression analysis where we studied the

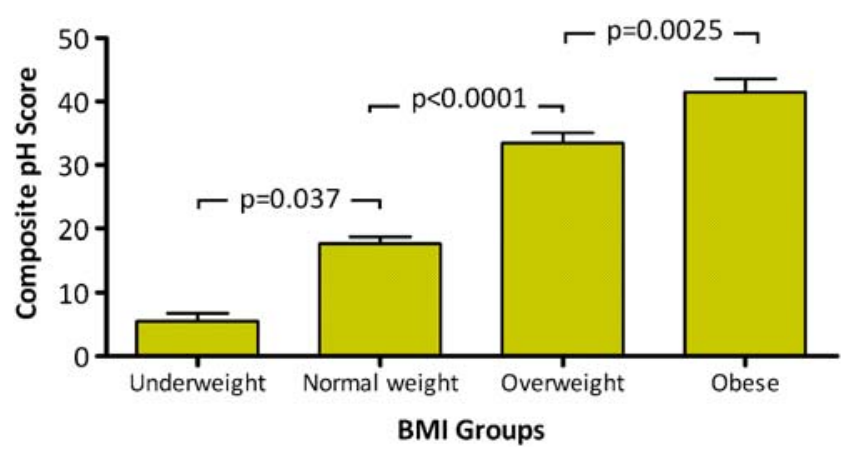

Figure 1 Composite $\mathrm{pH}$ score (mean, SE) across BMI groups. A significant difference between all BMI groups was observed $(p<$ 0.0001, ANOVA). Post hoc tests used to calculate the statistical significance of differences between each two adjacent individual BMI groups. linear relationship between esophageal acid exposure with BMI.

Multiple Regression Analysis

We studied the relationship of each measure of esophageal acid exposure with BMI using age, sex, hiatal hernia, and LES status as regressors. Table 4 provides the adjusted slope (increase in $\mathrm{pH}$ parameter per unit increase of BMI), $95 \%$ confidence interval, and percent of variation explained by BMI $\left(R^{2}\right)$. For each component, the adjusted increase in that component per unit increase of BMI was significant $(p<0.0001)$. On the basis of the adjusted $R^{2}$ value, $13 \%$ of the variability in the composite $\mathrm{pH}$ score may be attributable to variation in BMI.

Each unit increase in BMI was associated with an increase in the composite pH score of 1.46 (95\% CI, 1.131.79) unit. This increase in composite $\mathrm{pH}$ score was higher in men [1.79, CI (1.18-2.39)] than in women [1.31, CI $(0.92-1.69)]$; however, the difference was not statistically significant $(p=0.19)$.

Table 3 Comparison of the Composite pH Score by Risk Factor

\begin{tabular}{lllll}
\hline Risk Factor & Subgroup & N & Mean \pm SD & $p$ value $^{\text {a }}$ \\
\hline Age & $\geq 55$ & 704 & $32.3 \pm 38.5$ & 0.004 \\
\multirow{2}{*}{ Sex } & $<55$ & 955 & $29.1 \pm 39.5$ & \\
\multirow{2}{*}{ Hiatal hernia } & Male & 824 & $35.5 \pm 40.3$ & $<0.0001$ \\
& Female & 835 & $25.4 \pm 37.3$ & \\
LES & Present & 715 & $33.7 \pm 38.4$ & $<0.0001$ \\
& Absent & 944 & $28.0 \pm 39.5$ & \\
& Defective & 776 & $20.7 \pm 25.4$ & $<0.0001$ \\
\hline
\end{tabular}

${ }^{\text {a }}$ Wilcoxon two-sample test 
Table 4 Multiple Regression Analysis for Esophageal 24-h pH Components and Composite $\mathrm{pH}$ Score on BMI Adjusted for Age, Sex, Hiatal Hernia, and LES Status

\begin{tabular}{lcccc}
\hline & Adjusted slope & $95 \%$ CI of slope & Adjusted $R^{2}$ & Adjusted $p$ value \\
\hline \% Total time & 0.35 & $0.24,0.46$ & 0.0869 & $<0.0001$ \\
\% Upright time & 0.37 & $0.11,0.63$ & 0.0254 & 0.0046 \\
\% Supine time & 0.38 & $0.26,0.50$ & 0.0795 & $<0.0001$ \\
Number of episodes & 4.41 & $3.44,5.38$ & 0.1275 & $<0.0001$ \\
Number of episodes $>5$ min & 0.18 & $0.13,0.23$ & 0.0949 & $<0.0001$ \\
Longest episode & 0.62 & $0.39,0.85$ & 0.0486 & $<0.0001$ \\
\% Post prandial time & 0.48 & $0.36,0.61$ & 0.0881 & $<0.0001$ \\
Composite pH score & 1.46 & $1.13,1.79$ & 0.1264 & $<0.0001$ \\
\hline
\end{tabular}

\section{Exploration for BMI Thresholds}

We further explored to determine if a threshold existed in BMI above or below which the positive relationship between $\mathrm{pH}$ and BMI ceased to exist. Table 5 shows the difference in the adjusted mean and $R^{2}$ for each cut point of BMI from 25 through 35 for the percent total time $\mathrm{pH}<4$. It can be observed that the relationship is constant and that there is no distinct threshold above which the effect of BMI is maximal.

\section{LES Status and BMI}

The prevalence of a mechanically defective LES increased in higher BMI groups ( $p<0.0001$, Fig. 2). Table 6 presents the adjusted odds ratio and 95\% CI for the risk of LES by different risk groups including BMI group, age, sex, and hiatal hernia status. Hiatal hernia and obesity and overweight were shown to have a significant effect on risk of a defective LES, but age and sex had no significant effect. The relative contribution of BMI and LES pressure to esophageal acid exposure was demonstrated by plotting these parameters in a three-dimensional graph. Figure 3 shows this interaction.

\section{Discussion}

Two common diseases of contemporary Western society are GERD and obesity. Despite the many parallels between their epidemiology and presumed etiology, the relationship between the two disease processes remains incompletely understood. The major finding of this study is that the degree of esophageal acid exposure is strongly associated with increasing weight. This was true whether BMI was examined either as a continuous variable or as a categorical variable. The relationship is even stronger after adjusting for the known effect of age, sex, hiatal herniation, and LES status. Other workers, including ourselves, have reported comparable findings in much smaller series. ${ }^{19-21}$ The major strength of the current study lies in the very large number of subjects studied, with a wide range of BMI and esophageal acid exposure.

For every unit increase in BMI, the percent total time $\mathrm{pH}<4$ increased by $0.35 \%$ (95\% CI, 0.24-0.46). This effect
Table 5 Exploration of BMI Cut Point for Detecting Difference in Percent Total Time $\mathrm{pH}<4$

Analysis of covariance on percent total time $\mathrm{pH}<4$ comparing $\mathrm{BMI}<$ and $\geq$ cut point adjusted for age, sex, hiatal hernia, and valve status

\begin{tabular}{lclcc}
\hline BMI cut-point & $\begin{array}{l}\text { Difference of } \\
\text { adjusted means }\end{array}$ & $\begin{array}{l}95 \% \text { CI for } \\
\text { difference }\end{array}$ & Adjusted $R^{2}$ & Adjusted $p$ value \\
\hline$<25$ vs. $\geq 25$ & -3.86 & $-5.17,-2.54$ & 0.0838 & $<0.0001$ \\
$<26$ vs. $\geq 26$ & -3.33 & $-4.56,-2.10$ & 0.0811 & $<0.0001$ \\
$<27$ vs. $\geq 27$ & -3.42 & $-4.64,-2.20$ & 0.0823 & $<0.0001$ \\
$<28$ vs. $\geq 28$ & -3.40 & $-4.63,-2.17$ & 0.0817 & $<0.0001$ \\
$<29$ vs. $\geq 29$ & -3.74 & $-5.00,-2.47$ & 0.0841 & $<0.0001$ \\
$<30$ vs. $\geq 30$ & -3.18 & $-4.52,-1.84$ & 0.0776 & $<0.0001$ \\
$<31$ vs. $\geq 31$ & -3.06 & $-4.50,-1.62$ & 0.0752 & $<0.0001$ \\
$<32$ vs. $\geq 32$ & -2.99 & $-3.55,-1.43$ & 0.0734 & 0.0002 \\
$<33$ vs. $\geq 33$ & -3.09 & $-4.82,-1.37$ & 0.0724 & 0.0004 \\
$<34$ vs. $\geq 34$ & -3.48 & $-5.37,-1.59$ & 0.0728 & 0.0003 \\
$<35$ vs. $\geq 35$ & -4.33 & $-6.43,-2.23$ & 0.0746 & $<0.0001$ \\
$<36$ vs. $\geq 36$ & -3.63 & $-6.04,-1.21$ & 0.0703 & 0.0032 \\
\hline
\end{tabular}




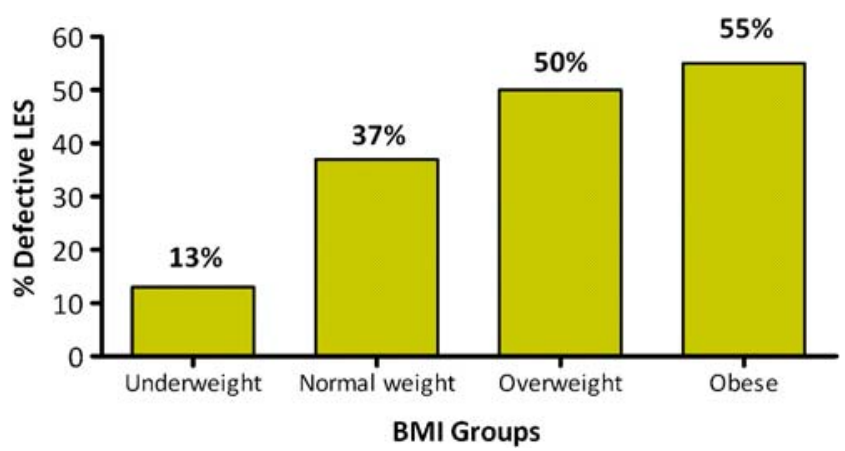

Figure 2 Prevalence of a defective LES across BMI groups $(p<$ 0.0001 , chi-square test).

of BMI on esophageal acid exposure appears to be continuous, since no particular BMI cutoff point was associated with a larger difference in the percent total time $\mathrm{pH}<4$ (Table 5). The $R^{2}$ value calculated by multiple regression analysis in our series indicates that $13 \%$ of the change in esophageal acid exposure may be explained by variation in the BMI. This degree of association is much greater than the values typically reported for other recognized relationships between BMI and obesity-related comorbidities. Studies correlating BMI and blood pressure have reported values ranging from $5 \%$ to $9 \%$, and the magnitude of correlation between BMI and blood sugar and high-density lipoprotein-cholesterol and triglycerides is even less. ${ }^{22,23}$

In concert with the greater degree of reflux observed in heavier subjects, we also observed a greater frequency of a mechanically defective LES. We found that age and sex have minimal effect on the status of the LES. Compared to patients with normal weight, obese patients were more than twice as likely to have a defective LES $[\mathrm{OR}=2.12(1.63$, 2.75)]. In those with a hiatal hernia, the likelihood of a defective LES was also twice as great as those without hiatal herniation $[\mathrm{OR}=2.36(1.93-2.89)]$. These two observations suggest that the effect of obesity on the LES status is almost as great as the effect of hiatal herniation.

Reflux of gastric juice usually results from either a defective LES or transient loss of LES pressure. We focused on the correlation between presence of a defective LES and increasing BMI. Other workers have reported that obesity is associated with increased frequency of transient lower esophageal sphincter relaxation. ${ }^{24}$ It is therefore clear that obesity has the potential to affect both these two mechanisms of reflux.

The effect of increasing BMI on the different components of $\mathrm{pH}$ record may shed light on the mechanism of obesity-induced reflux. For each unit increase in BMI, the increase in percent post prandial time was 0.48 compared to 0.35 for the percent total time. This may reflect the eating habit of obese subjects.

We also found that the association between BMI and esophageal acid exposure was stronger during the supine period compared to the upright position. One potential explanation is that the influence of increased intraabdominal pressure found in obesity may be maximal in the supine position.

The relative contribution of BMI and LES status to esophageal acid exposure can be conceptualized in a three-dimensional model showing the interaction between BMI and LES and esophageal acid exposure. As BMI increases and the status of the LES deteriorates, esophageal acid exposure peaks, suggesting an additive effect (Fig. 4).

We acknowledge several limitations of this study. The absence of endoscopic data in the study subjects precludes any comment on the relation between BMI and esophageal mucosal damage. The identification of hiatal herniation in the study population was based on manometric criteria since consistent radiologic information was not available for all subjects. However, manometric identification of hiatal herniation has been reported to be highly specific when compared to endoscopic evaluation. ${ }^{25}$ The sensitivity of our manometric identification appears higher than that of the other reports, most likely because of the greater accuracy of identifying the double hump in the artifactfree tracings produced by the slow motorized pull-through technique. ${ }^{18,25}$

Another potential limitation is selection bias related to the referral pattern of the subjects. Although our esoph-
Table 6 Logistic Regression Analysis for LES Status on BMI Group, Age, Sex and Hiatal Hernia Adjusted for Parameters in the Model

Number of cases in model, 1,659 (776 defective valve; 883 normal valve). $R^{2}, 0.0942$

\begin{tabular}{lccc}
\hline Parameter & Adjusted OR & $95 \%$ CI & Adjusted $p$ value \\
\hline BMI group & & & \\
Obese vs. normal & 2.115 & $1.632,2.747$ & $<0.0001$ \\
Overweight vs. normal & 1.687 & $1.320,2.161$ & $<0.0001$ \\
Underweight vs. normal & 0.238 & $0.037,0.880$ & 0.0620 \\
Age: per year increase & 1.004 & $0.996,1.011$ & 0.3211 \\
Sex: male vs. female & 1.021 & $0.831,1.254$ & 0.8418 \\
Hiatal hernia: present vs. absent & 2.359 & $1.926,2.894$ & $<0.0001$ \\
\hline
\end{tabular}


Figure 3 Interaction between

LES resting pressure, BMI, and esophageal acid exposure in all subjects $(n=1659)$.

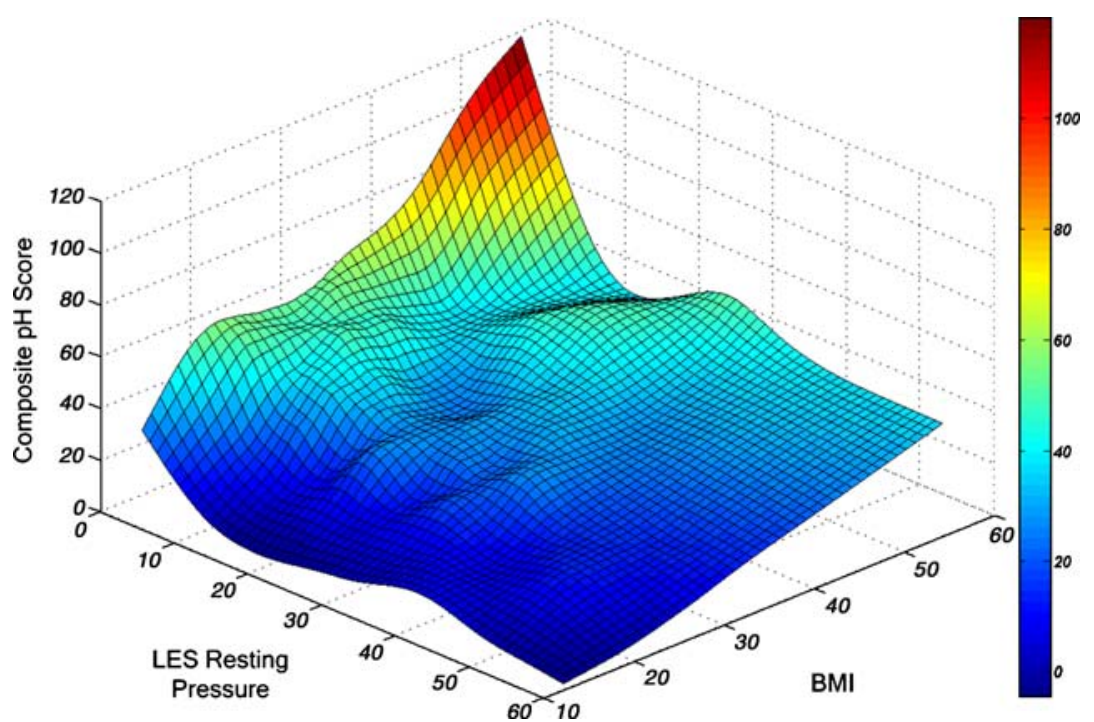

ageal laboratory is a recognized referral center for patients with complex esophageal diseases, we deliberately excluded those complex patients such as those with prior gastric or esophageal surgery, or with named motility disorders, whose results would be irrelevant to the understanding of the general relationship. It is also important to emphasize that subjects were referred to the diagnostic esophageal laboratory for the physiologic studies and not specifically for a surgical opinion. We recognize that the subjects in this study were all symptomatic patients, and the findings cannot be extrapolated to the asymptomatic population.

This relationship between BMI and esophageal acid exposure suggests that the same environmental influences are responsible for the epidemic of both diseases in contemporary Western society. There is evidence that the volume and fat content of the diet are associated with increased esophageal acid exposure. ${ }^{26}$ In addition, high caloric diets have been shown to increase esophageal acid exposure. ${ }^{27,28}$ It is therefore likely that the same dietary habits can promote both diseases. The healthcare implications of our study are potentially far reaching. For example, the reduction of weight by surgical or pharmacological intervention has reduced obesity-related comorbidities such as diabetes and cardiovascular disease: the possibility that weight reduction may also reduce or prevent the development of the complications of GERD, including reflux-induced lung disease, Barrett's esophagus, and esophageal adenocarcinoma, is ripe for further study.
Figure 4 Interaction between LES status, BMI, and esophageal acid exposure in all subjects $(n=1659)$. LES status stratified on an ordinal scale of $0-3$, according to the number of LES components (resting pressure and total and abdominal length) within the normal range: 0 all components defective, 1 only one component normal, 2 two components normal, 3 all three components normal.

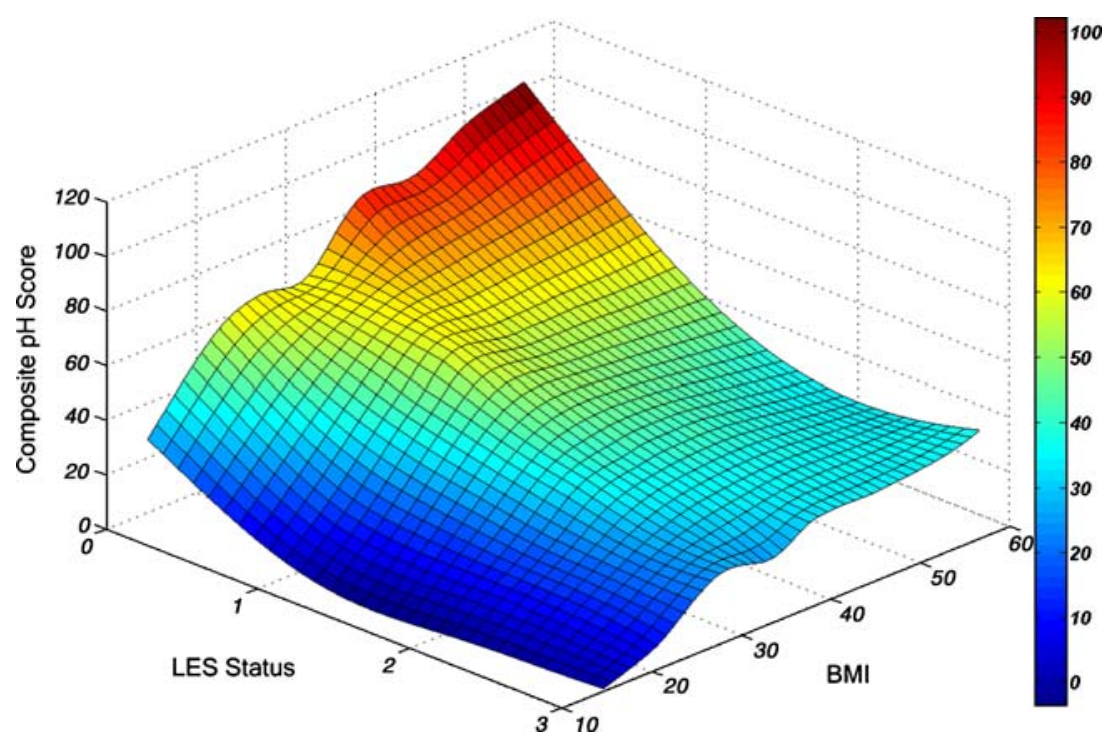


Open Access This article is distributed under the terms of the Creative Commons Attribution Noncommercial License which permits any noncommercial use, distribution, and reproduction in any medium, provided the original author(s) and source are credited.

\section{References}

1. Dent J, El-Serag HB, Wallander MA, et al. Epidemiology of gastroesophageal reflux disease: a systematic review. Gut 2005;54:710-717. doi:10.1136/gut.2004.051821.

2. El-Serag HB. Time trends of gastroesophageal reflux disease: a systematic review. Clin Gastroenterol Hepatol 2007;5(1):17-26. doi:10.1016/j.cgh.2006.09.016.

3. Flegal KM, Carroll MD, Ogden CL, et al. Prevalence and trends in obesity among US adults, 1999-2000. JAMA 2002;288:17231727. doi:10.1001/jama.288.14.1723.

4. Ogden CL, Carroll MD, Curtin LR, et al. Prevalence of overweight and obesity in the United States, 1999-2004. JAMA 2006;295:1549-1555. doi:10.1001/jama.295.13.1549.

5. Ruhm CJ. "Current and future prevalence of obesity and severe obesity in the United States" (June 2007). National Bureau of Economic Research (NBER) Working Paper No. W13181, at: http://ssrn.com/abstract=994229.

6. Corley DA, Kubo A. Body mass index and gastroesophageal reflux disease: a systematic review and meta-analysis. Am J Gastroenterol 2006;108:2619-2628.

7. Lagergren J, Bergstrom R, Nyren O. No relation between body mass and gastro-oesophageal reflux symptoms in a Swedish population based study. Gut 2000;47:26-29. doi:10.1136/gut.47.1.26.

8. Locke GR 3rd, Talley NJ, Fett SL, et al. Risk factors associated with symptoms of gastroesophageal reflux. Am J Med 1999;106:642-649. doi:10.1016/S0002-9343(99)00121-7.

9. Ruhl CE, Everhart JE. Overweight, but not high dietary fat intake, increases risk of gastroesophageal reflux disease hospitalization: the NHANES I Epidemiologic Followup Study. First National Health and Nutrition Examination Survey. Ann Epidemiol 1999;9:424-435. doi:10.1016/S1047-2797(99)00020-4.

10. Murray L, Johnston B, Lane A, et al. Relationship between body mass and gastrooesophageal reflux symptoms: the Bristol Helicobacter Project. Int J Epidemiol 2003;32:645-650. doi:10.1093/ije/dyg108.

11. Nandurkar S, Locke GR III, Fett S, et al. Relationship between body mass index, diet, exercise, and gastro-oesophageal reflux symptoms in a community. Aliment Pharmacol Ther 2004;20: 497-505. doi:10.1111/j.1365-2036.2004.02156.x.

12. Nilsson M, Lundegardh G, Carling L, et al. Body mass and reflux oesophagitis: an oestrogen-dependent association? Scand J Gastroenterol 2002;37:626-630. doi:10.1080/00365520212502.

13. Wu AH, Tseng CC, Bernstein L. Hiatal hernia, reflux symptoms, body size, and risk of esophageal and gastric adenocarcinoma. Cancer 2003;98:940-948. doi:10.1002/cncr.11568.
14. Incarbone R, Bonavina L, Szachnowicz S, et al. Rising incidence of esophageal adenocarcinoma in Western countries: is it possible to identify a population at risk? Dis Esophagus 2000;13:275-278. doi:10.1046/j.1442-2050.2000.00132.x.

15. El-Serag HB, Graham DY, Satia JA, et al. Obesity is an independent risk factor for GERD symptoms and erosive esophagitis. Am J Gastroenterol 2005;100:1243-1250. doi:10.1111/j.1572-0241.2005.41703.0078.

16. Zaninotto G, DeMeester TR, Schwizer W, et al. The lower esophageal sphincter in health and disease. Am J Surg 1988;155 (1):104-111. doi:10.1016/S0002-9610(88)80266-6.

17. Campos GM, Oberg S, Gastal O, et al. Manometry of the lower esophageal sphincter: inter- and intraindividual variability of slow motorized pull-through versus station pull-through manometry. Dig Dis Sci 2003;48(6):1057-1061. doi:10.1023/ A:1023700309299.

18. Klaus A, Raiser F, Swain JM, et al. Manometric components of the lower esophageal double hump. Dig Dis 2000;18(3):172-177. doi:10.1159/000051391.

19. El-Serag HB, Ergun GA, Pandolfino J, et al. Obesity increases oesophageal acid exposure. Gut 2007;56(6):749-755. doi:10. 1136/gut.2006.100263.

20. Wajed SA, Streets CG, Bremner CG, et al. Elevated body mass disrupts the barrier to gastroesophageal reflux. Arch Surg 2001;136(9):1014-1018. doi:10.1001/archsurg.136.9.1014.

21. Herbella FA, Sweet MP, Tedesco P, et al. Gastroesophageal reflux disease and obesity. Pathophysiology and implications for treatment. J Gastrointest Surg 2007;11(3):286-290. doi:10.1007/ s11605-007-0097-z.

22. Wakabayashi I, Masuda H. Obesity increases the risk of development of atherosclerosis in elderly type 2 diabetic patients. Geriatr Gerontol Int 2005;5:17-21. doi:10.1111/j.1447-0594.2005. 00133.x.

23. Mufunda J. Body mass index and blood pressure: where are we now? J Hum Hypertens 2007;21(1):5-7. doi:10.1038/sj. jhh.1002106.

24. Wu JC, Mui LM, Cheung CM, et al. Obesity is associated with increased transient lower esophageal sphincter relaxation. Gastroenterology 2007;132(3):883-889. doi:10.1053/j.gastro.2006.12.032.

25. Agrawal A, Tutuian R, Hila A, et al. Identification of hiatal hernia by esophageal manometry: is it reliable? Dis Esophagus 2005;18:316-319. doi:10.1111/j.1442-2050.2005.00506.x.

26. Iwakiri K, Kobayashi M, Kotoyori M, et al. Relationship between postprandial esophageal acid exposure and meal volume and fat content. Dig Dis Sci 1996;41(5):926-930. doi:10.1007/ BF02091532.

27. Fox M, Barr C, Nolan S, Lomer M, et al. The effects of dietary fat and calorie density on esophageal acid exposure and reflux symptoms. Clin Gastroenterol Hepatol 2007;5(4):439-444. doi:10.1016/j.cgh.2006.12.013.

28. Colombo P, Mangano M, Bianchi PA, et al. Effect of calories and fat on postprandial gastro-oesophageal reflux. Scand J Gastroenterol 2002;37(1):3-5. doi:10.1080/003655202753387266. 